\title{
El urólogo y las nuevas dianas terapéuticas en el cáncer renal avanzado
}

\author{
Arango Toro O. \\ Servicio de Urología. Hospital del Mar. Barcelona \\ Actas Urol Esp. 2008;32(9):865-867
}

$T$ radicionalmente el urólogo ha tenido un papel fundamental en la atención médica del cáncer renal y ha asumido casi en exclusiva todos los pasos del proceso diagnóstico, el tratamiento y el seguimiento posterior. Hasta ahora, el tratamiento del cáncer renal había sido básicamente quirúrgico y el urólogo se había preocupado por asumir todos los avances e innovaciones tecnológicas que han ido apareciendo, tanto para el tratamiento de los tumores pequeños, como para la cirugía de las grandes masas renales. Además, fueron los urólogos los que en su día se interesaron por definir los factores pronóstico que determinan el riesgo de recidiva tumoral tras el tratamiento quirúrgico y se preocuparon por utilizar en sus pacientes los tratamientos adyuvantes que han demostrado algún grado de eficacia, hasta hace poco tiempo, representados casi exclusivamente por las citoquinas ${ }^{1}$.

Recientemente, la FDA de los Estados Unidos y la EMEA Europea aprobó la utilización de los nuevos fármacos inhibidores de las quinasas para el tratamiento del cáncer renal avanzado, lo que representa un nuevo reto para el urólogo y exige un cambio de actitud respecto al futuro, pues muy posiblemente las próximas generaciones de urólogos utilizarán cada vez más éste tipo de tratamientos en las diversas neoplasias, que probablemente darán como resultado final la cronificación del cáncer.

Hasta hace poco tiempo, el único tratamiento efectivo del cáncer renal era la cirugía, pero cuando ésta llegaba tarde, el pronóstico de estos pacientes era muy pobre, con un tiempo medio de progresión tumoral de 2,4 meses y una supervivencia media desde la aparición de metástasis inferior a 10 meses $^{2}$. En estos casos las opciones terapéuticas eran muy escasas, y después de haberse probado más de 100 citostáticos diferentes e infinidad de combinaciones entre ellos, con tasas de respuesta poco consistentes e inferiores al 10\%, se asumió que el cáncer renal era un tumor quimiorresistente y prácticamente se abandonó esta vía de tratamiento ${ }^{3}$.
Posteriormente, se logró un pequeño avance tratando a estos pacientes con interferón- $\alpha$ e interleuquina-2, con lo que la inmunoterapia pasó a ser el tratamiento de elección en los tumores renales avanzados tras realizar una cirugía citorreductora. Con el tratamiento con las citoquinas se obtiene una tasa global de respuesta de un 5-15\% en casos bien seleccionados, pero con una duración muy corta en el tiempo y una elevada tasa de efectos adversos $^{4-7}$. Por todo ello se imponía el desarrollo de nuevas opciones terapéuticas para estos pacientes.

Finalmente, la situación del cáncer renal avanzado está cambiando de manera considerable con las nuevas dianas terapéuticas, mediante la utilización de moléculas específicamente diseñadas para actuar en pasos concretos y bien conocidos del ciclo celular de estos tumores. Varias de estas sustancias han demostrado su eficacia en ensayos clínicos en fase III, habiéndose demostrado una diferencia estadísticamente significativa en la supervivencia global frente al placebo en pacientes con cáncer renal metastático. Según su mecanismo de acción estos nuevos fármacos pueden dividirse en tres grandes grupos: 1- Los inhibidores de la tirosinquinasa: Sorafenib (Nexavar ${ }^{\circledR}$ ) y Sunitinib (Sutent ${ }^{\circledR}$ ), que actúan sobre una serie de quinasas implicadas en la proliferación celular y en la angiogénesis. 2- Los inhibidores de la m-TOR (mammaliam Target of rapamycin): Tensirolimus (Torise ${ }^{\circledR}$ ) y Everolimus (aún no registrado con esta indicación en Europa), que actúan sobre esta proteína con actividad quinasa, implicada en los procesos de regulación, crecimiento y supervivencia de la célula tumoral. 3- Los anticuerpos monoclonales recombinantes antiVEGF: Bevacizumab (Avastin $\left.{ }^{\circledR}\right)^{8-13}$.

Del análisis de los resultados publicados en la literatura médica, se deduce que 2/3 partes de los pacientes con un tumor renal metastásico se pueden beneficiar clínicamente del tratamiento con los fármacos inhibidores de las multiquinasas, de los inhibidores de la m-TOR o de su combinación. 
Todos ellos, excepto el Tensirolimus se administran por vía oral, de forma ambulatoria y poseen un buen perfil de seguridad. El Tensirolimous se administra por vía endovenosa una vez a la semana y puede ser aplicado ambulatoriamente en la consulta o en hospital de día. En general, los efectos secundarios de estos fármacos suelen ser en su mayoría de grado 1 y 2 según los CCT (Common Toxicity Criteria), siendo muy infrecuentes los efectos adversos severos de grado 3 y 4, por lo que se consideran fármacos seguros y de fácil manejo ${ }^{14,15 .}$

Respecto a la toxicidad de estos fármacos, se acaba de publicar una completísima revisión que analiza la experiencia acumulada en literatura médica hasta el momento, y aporta una serie de recomendaciones sobre la prevención y el tratamiento de los principales efectos adversos. Los autores llegan a la conclusión de que los efectos adversos graves con los tres fármacos (Sorafenib, Sunitinib y Tensirolimus) son poco frecuentes y en su mayoría pueden ser manejados médicamente, sin que se tenga que suspender el tratamiento o reducir la dosis, con la consiguiente mengua en la eficacia del tratamiento ${ }^{16}$.

Además de los fármacos anteriormente descritos, en este momento la industria farmacéutica está desarrollando una gran cantidad de fármacos, químicamente emparentados con los anteriores, y es lógico suponer que en pocos años dispondremos de una amplia gama de fármacos más específicos, más efectivos y más seguros, con lo que la supervivencia prolongada en carcinoma renal avanzado será una realidad. Por todo ello, es importante que el urólogo cambie el enfoque eminentemente quirúrgico que siempre ha tenido del cáncer renal y se interese por los nuevos tratamientos médicos, como lo hizo en su día con el tratamiento hormonal del cáncer de próstata avanzado o con el tratamiento endovesical del cáncer vesical superficial.

Hasta ahora, no se ha documentado ninguna respuesta completa con estos fármacos y la supervivencia que se obtiene con ellos es aún limitada en el tiempo. Así, en un gran estudio multicéntrico realizado en 903 pacientes, la supervivencia libre de enfermedad fue de 5,5 meses en el grupo con Sorafenib frente a 2,8 en el grupo placebo ${ }^{8}$. Y en otro importante estudio realizado por el MSKCC de Nueva York en 750 pacientes con cáncer renal metastático, la supervivencia libre de progresión fue de 11 meses en el grupo de Sunitinib contra 5 meses en el grupo de Interferón- $\alpha^{14}$. Sin embargo, aún se desconocen muchos aspectos relacionados con estos fármacos, que muy posiblemente contribuirán a mejorar los resultados, como por ejemplo cuál de ellos es el más efectivo en determinadas subpoblaciones de pacientes según el número y localización de las metástasis, o frente a los diversos tipos de tumor. Así como tampoco se conoce cuál es el mejor esquema de tratamiento, qué beneficio clínico puede aportar la escalada de dosis, durante cuanto tiempo se debe mantener el tratamiento, qué resultados se pueden obtener asociando dos o más de estos fármacos, o empleándolos conjuntamente con otros tipos de tratamiento. Por último, también queda por determinar cual es el valor real de la cirugía citorreductora previa al tratamiento con estas nuevas sustancias, como se demostró en su día con la inmunoterapia.

Por todo ello, considero primordial que los urólogos estemos familiarizados y conozcamos todos los aspectos relacionados con el uso de estas nuevas moléculas para ofrecer a nuestros pacientes el mejor tratamiento adyuvante tras la cirugía. Asimismo es importante que los urólogos participemos activamente en el diseño y la inclusión de pacientes en ensayos clínicos con estos fármacos, los cuales actualmente son necesarios para dilucidar las numerosas dudas e interrogantes que aún se tienen con estos tratamientos, los cuales fueron mencionados anteriormente. Un cambio de actitud frente a estos nuevos tratamientos por parte de los urólogos, conseguirá ampliar el marco de las terapias adyuvantes tras la cirugía del cáncer renal avanzado, lo que redundará no solo en favor de los pacientes, sino también de la especialidad, de nosotros mismos y de las futuras generaciones de urólogos.

\section{REFERENCIAS}

1. Carballido J, Oliver C. Tratamiento del carcinoma renal metastático. En: Tratado de Oncología Urológica. Resel L, Moreno J, editores. Sanidad y Ediciones S.L. 2003;Cap. 31:399-413.

2. Jemal A, Siegel R, Ward E, Murray T, Xu J et al. Cancer statistics, 2006. CA Cancer J Clin. 2006;56:106-130.

3. Oevermann K, Buer J, Hoffmann R, Franzke A, Schrader A et al. Capecitabine in the treatment of metastatic renal cell carcinoma. Br J Cancer. 2000;83:583-587.

4. Negrier S, Gomez F, Douillard JY, Ravaud A, Chevreau C et al. Groupe Français d'Immunothérapie. Prognostic factors of response or failure of treatment in patients with metastatic renal carcinomas treated by cytokines: a report from the Groupe Français d'Immunothérapie. World J Urol 2005;23:161-165. 
5. McDermott DF, Rini BI. Immunotherapy for metastatic renal cell carcinoma. BJU Int. 2007;99:1282-1288.

6. Herrmann E, Brinkmann OA, Bode ME, Bierer S, Köpke T et al. Histologic subtype of metastatic renal cell carcinoma predicts response to combined immunochemotherapy with interleukin 2, interferon alpha and 5-fluorouracil. Eur Urol 2007;51:1625-1631.

7. Negrier S, Perol D, Ravaud A, Chevreau C, Bay JO et al. For The French Immunotherapy Intergroup. Medroxyprogesterone, interferon alfa-2a, interleukin 2 , or combination of both cytokines in patients with metastatic renal carcinoma of intermediate prognosis: results of a randomized controlled trial. Cancer. 2007;110:2468-2477.

8. Yang JC. Bevacizumab for patients with metastatic renal cancer: an update. Clin Cancer Res. 2004;10:6367S-6370S.

9. Escudier B, Eisen T, Stadler WM, Szczylik C, Oudard S et al. TARGET Study Group. Sorafenib in advanced clear-cell renalcell carcinoma. N Engl J Med. 2007;356:125-134.

10. Motzer RJ, Basch E. Targeted drugs for metastatic renal cell carcinoma. Lancet. 2007;370:2071-2073.

11. Motzer RJ, Hutson TE, Tomczac P, Michaelson MD, Bukowski RM et al. Sunitinib versus Interferon alfa in metastatic renalcell carcinoma. N Engl J Med. 2007;356:115-124.

12. Choueiri TK, Plantade A, Elson P, Negrier S, Ravaud A et al. Efficacy of sunitinib and sorafenib in metastatic papillary and chromophobe renal cell carcinoma. J Clin Oncol. 2008;26:127-131.
13. Bellmunt J, Montagut C, Albiol S, Carles J, Maroto P, Orsola A. Present strategies in the treatment of metastatic renal cell carcinoma: an update on molecular targeting agents. BJU Int. 2007;99:274-280

14. Hudes G, Carducci M, Tomczak P, Dutcher J, Figlin R, et al. Temsirolimus, Interferon alfa, or both for advanced renal-cell carcinoma. N Eng J Med. 2007;356:2271-2281.

15. Patard J-J, Rioux-Leclercq N, Fergelot P. Understanding the importante of smart drugs in renal cell carcioma. Eur Urol. 2006;49:633-643.

16. Bhojani N, Jeldres C, Patard JJ, Perrotte P, Suardi N et al. Toxicities associated with the administration of sorafenib, sunitinib, and temsirolimus and their management in patients with metastatic renal cell carcinoma. Eur Urol 2008;53:917930

Correspondencia autor: Dr. O. Arango Toro

Servicio de Urología

Hospital del Mar

Passeig Maritim, 25-29 - 08003 Barcelona

Tel.: 932483000

E-mail autor: oarango@imas.imim.es

Información artículo: Editorial

Trabajo recibido: mayo 2008 